\title{
Roles in Innovative Software Teams: A Design Experiment
}

\author{
Ivan Aaen \\ Department of Computer Science, \\ Aalborg University, \\ DK-9220 Aalborg East, Denmark
}

\begin{abstract}
With inspiration from role-play and improvisational theater, we are developing a framework for innovation in software teams called Essence. Based on agile principles, Essence is designed for teams of developers and an onsite customer. This paper reports from teaching experiments inspired by design science, where we tried to assign differentiated roles to team members. The experiments provided valuable insights into the design of roles in Essence. These insights are used for redesigning how roles are described and conveyed in Essence.
\end{abstract}

Keywords: Software innovation, roles, innovation in teams, design science.

\section{Introduction}

This paper takes its point of departure in two observations: (1) in a global economy, software development in high-cost countries will increasingly depend on the ability to create high-value products in close collaboration with sophisticated customers; and (2) agile development opens up new opportunities for software innovation by allowing for changes and adaptations late in development projects (de la Barra and Crawford 2007; Highsmith 2004; Highsmith and Cockburn 2001; Judy and KruminsBeens 2007; Nerur and Balijepally 2007).

Based on these premises and the assumption that software innovation may lead to high-value software products, this paper focuses on software innovation and innovative software teams using agile development principles. More precisely, the paper is about facilitating innovation in agile software teams by assigning particular roles to team members. We wish to know how roles can be defined to support creative interaction in the team.

The paper reports from two teaching experiments. The experiments revealed some problems in the design of Essence roles and how they are related to team members.

\section{Creativity in Teams}

In recent years, an increasing amount of research focuses on creativity in development teams: Leenders et al. (2007) discuss the relation between method and creativity in team-based product development in general. They conclude that methods and 
creativity are supportive of each other. As an alternative to using methods, Fortino (2008) proposes the use of pattern languages for innovation management.

A number of authors investigate the method/creativity relation specifically with software development in mind. Some advocate creative and innovative software development based on agile principles (Highsmith 2004; Highsmith and Cockburn 2001). Chang (2008) advocates sequential techniques that are collaborative, heuristic, and normatively guided. Tiwana and McLean (2005) investigate how expertise and creativity integrates in teams. Finally, a number of authors have investigated how infrastructures support creative work. Some address general work environments for any kind of development (Adamides and Karacapilidis 2006; Deshpande et al. 2004; Do and Gross 2007; Greene 2002; Johansson et al. 2002; Kristensen 2004; Lewis and Moultrie 2005; Satzinger et al. 1999; Terrenghi et al. 2006; Thomas et al. 2002), while others address software development more specifically (Shneiderman 1999, 2002, 2007). Some research focuses on physical infrastructures (Deshpande et al. 2004; Do and Gross 2007; Greene 2002; Johansson et al. 2002; Kristensen 2004; Lewis and Moultrie 2005; Terrenghi et al. 2006), whereas others focus on virtual environments (Adamides and Karacapilidis 2006; Satzinger et al. 1999, Schneiderman 1999, 2002, 2007; Thomas et al. 2002).

Within software requirements engineering, researchers such as Maiden and Mich have made contributions on creativity. Maiden and colleagues have experimented with innovative techniques to encourage creative thinking about requirements (Maiden, Manning, Robertson, and Greenwood 2004; Maiden and Robertson 2005; Maiden, Robertson and Gizikis 2004; Maiden, Robertson, and Robertson 2006), and pointed to improvisational theater as a possible source of new methods for requirements engineering (Mahaux and Maiden 2008). Mich et al. (2004) propose the use of a pragmatic communication model in a 16-step process applying a different user's viewpoint in each step.

Essence seeks to base software innovation on agile principles such as incremental development, low ceremony, and heterogeneous teams of customers and developers. The ambition is to widen the creative phase in a project to more than just the requirements part. Some of the ideas in Essence were presented in one conference and one journal paper in 2008 (Aaen 2008a, 2008b). Essence is very much a work-inprogress and a comprehensive description of Essence has not been published.

\section{Design Science and Essence}

Our research is concerned with the design of Essence: How can we facilitate innovative software development in teams? Being an experimental design effort, design research (Hevner et al. 2004; Vaishnavi and Kuechler 2004) is a suitable framework. According to Vaishnavi and Kuechler design research projects proceed through a series of sequential steps with feedback loops between the steps. The steps are (1) awareness of problem, (2) suggestion, (3) development, and (4) evaluation.

Designing a development method is a wicked problem (Rittel and Webber 1973) in the sense that the goals are fuzzy, there are no criteria to define a correct solution, there is no way to test if a solution meets its goals, and there is no way to control and 
repeat experiments. The use of the four steps, therefore, requires adaptation and common sense.

A development method such as Essence is too complicated to design and test all at once, but breaking up the design process in smaller parts introduces problems related to interdependencies between the parts. To reduce this dilemma, our experiments on design elements attempt to employ the full Essence framework.

We have covered all four steps in previous papers (Aaen 2008a, 2008b) primarily investigating the use of physical space and logical views in Essence. The present experiments cover two variations of team roles mainly covering the development and evaluation steps and how they feed back into the suggestion step (Figure 1).

In our research we combine four command variables (Simon 1996) to attain our design goals (Aaen 2008b):

1. Extending the window of opportunity.

2. Innovation management.

3. Innovation process support.

4. Mental model change.

The team role variations touch on combinations of the last two command variables. Innovation process support focuses on support for creativity, and on team learning. Mental model change focuses on the contrasting of views to spark off change in mental models, and on team integration. Essentially, we can vary these two command variables in our design of team roles: We can define the mindsets of roles in various ways, and similarly we can vary how the roles are employed. The lessons learned will result in changing team roles and/or other elements in Essence.

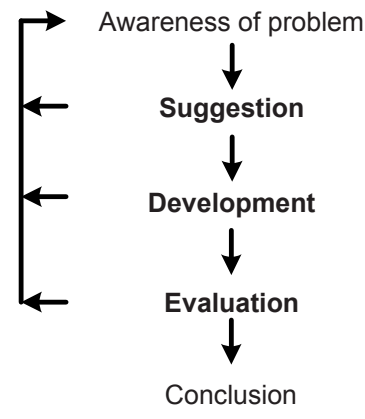

Fig. 1. The Design Cycle Used (Adapted from Vaishnavi and Kuechler 2004)

\section{Essence: A Method Concept for Software Innovation}

Since August 2006, we have experimented with infrastructures and methods to facilitate creativity and innovation in software development. We aim to build creative settings for team-based software development using modern development principles. These principles allow for flexible and incremental development and thus for incorporating new ideas even late in a project. We expect these principles to widen the 
window of opportunity for creativity and innovation by allowing learning experiences and discoveries from an ongoing project to feed ideas back into the project itself.

The main thrust in our research is the design of Essence. Among the ideas are:

- $\quad$ supporting creativity and innovation through all phases in the development project

- $\quad$ integrating into and extending existing development methods

- melding creative sessions with agile development to increase development speed and maintain flexibility in the project

- entrusting the development team-rather than external specialists-to be creative

- $\quad$ collective idea-generation in self-organizing teams

- $\quad$ using multiple perspectives to support divide-and-conquer strategies

- maintaining holistic overview via systematic separation

- kinesthetic thinking-using physical location and movement to support simulation and idea generation (Larssen et al. 2007)

We call Essence a method concept, not a method per se, to stress that Essence will find its actual form as the individual teams use and adapt it through daily routines, and integrate Essence into their main development method-for example, Scrum (Schwaber and Beedle 2002).

To support multiple perspectives we find inspiration in the four generic views: Earth, Water, Fire, and Air named by Empedocles of Acragas (ca. 495- 435 BCE). In his Tetrasomia, or Doctrine of the Four Elements, Empedocles argued that all matter is comprised of these four elements. Essence is named after Quintessence, the cosmic fifth element added by Aristotle to complement the four earthly elements.

Essence is intended to be lightweight, easy, and fun to use. Lightweight in the sense that ceremony and project overheads are kept at a minimum, so as not to have projects leave out Essence for lack of time. Easy to use in the sense that the time needed before Essence is useful should be short, and the activities in Essence should come naturally to the participants. Finally, it should be fun to use, to raise motivation.

The strategy for making Essence lightweight, easy, and fun to use is to organize creativity sessions in Essence as games similar to role playing games and improvisational theater (Swartjes and Vromen 2007; Yardley-Matwiejczuk 1997). Games are based on characters (roles), settings (infrastructure), and situations (games), whereas the events and actions are largely developed via disciplined improvisations. Both characters and settings are permanent elements of the development project to make the games a natural continuation of everyday life.

Essence has three basic design elements: views, modes, and roles.

\subsection{Views}

The views form the main part of the setting. The setting frames the story world in improvisational theater terms - the shared world that forms the basis for expressing each character's ideals (Swartjes and Vromen 2007). The setting for the software team consists of a physical infrastructure-the room where team members work.

Views provide a conceptual division of problem spaces, and balance overview with detail. Essence maps the software engineering 4P model (Bernstein and Yuhas 2005; 
Pressman 2005) onto the aforementioned four generic views. The views are used at all times and not only during Essence sessions. The views in Essence are product, project, process, and people. These views are represented on separate boards to support kinesthetic thinking.

The product view. Essence stimulates creative dialogue between customers and developers in order to develop ambitious technical responses to application area challenges. The product view represents the product being built - the source code, the system architecture, etc.- - to make the product and propositions for changes to it more tangible in team discussions.

The project view supports the customer in maintaining project status and planning throughout the project. This view gives an overview of project status.

The process view. Essence offers a repertoire of creative methods, tools, and techniques. The process view provides an overview of and access to this repertoire.

The people view visualizes organizational contexts, use scenarios, and interactions via mock-ups and simulations. Discussions on system features and user interfaces will primarily take place using this view.

\subsection{Modes}

Having defined the setting, the next step is to introduce a dynamic element: The situation that completes the story world. The first part of this comes in the form of creativity sessions called Essence Games, inspired by Hohmann's (2006) innovation games and numerous methods described in Huczynski (2001). Games are based on the principle of saying yes-accepting all offers that other characters bring into the situation (Swartjes and Vromen 2007).

Essence adapts to the project via three modes: idea, planning, and growing. Idea is for suggesting possible courses of action, for developing concepts and visions. This mode involves explorations, experiments, brainstorming, scenario development, experiments, etc. Creativity sessions in this mode are mainly exploratory. Planning involves decisions regarding what to do, when, and by whom. Creativity sessions in this mode focus mainly on inventory building to identify tasks. Growing is where ideas find actual form via evolution, trial, selection, maturation, expansion, enlargement, and progress. Creativity sessions are mainly confirmatory, and investigate if an appropriate level of innovation is reached in the project.

Modes have not been explored to any extent yet and will not be described further in this paper. The experiments reported on in this paper addressed the Idea mode.

\subsection{Roles}

Together, views and modes form a basis for the creative activities. Essence employs roles extensively to promote the application of multiple perspectives, and particularly to strengthen synergies between customer challenges and developer ambitions.

The role concept is quite difficult to define, as pointed out by YardleyMatwiejczuk (1997). We use the term in a simple structuralist sense to denote the rights, duties, and expectations of an individual, as he or she participates in a social context. Thus, the role follows from a combination of socialization, social position, and the organizational context of the team. 
There are four roles in Essence defining four characters: challenger, responder, anchor, and child. Except for the child role, these roles are permanent as a team member usually has the same role throughout the project. The roles aim to introduce different personal perspectives and expertise to the team (Tiwana and McLean 2005).

Each role has a clear raison d'être (Swartjes and Vromen 2007). The challenger is the on-site customer posing project requirements in the form of challenges. The responder is the developer employing technical competence to deliver ambitious responses. These two roles engage in dialogues where solutions are developed by contrasting application area needs and desires with technical opportunity. The anchor serves to keep the team absorbed and focused on delivering exciting solutions. The last role is the child; this role is fleeting in the sense, that anyone can suspend his permanent role and temporarily take the child role at any time. The child is irresponsible and may raise any idea or issue he or she sees fit—even when this is contrary to decisions made earlier by the team. This role is named after the child in The Emperor's New Clothes who said "but he hasn't got anything on," and thereby revealed the emperor's folly. The child is a supplier of ideas and visions, but also a safety valve in heated discussions.

\section{Designing the Roles in Essence}

Up to now, Essence has been developed primarily in an educational setting involving thesis work and a new course on software innovation for graduate students. This setting allows for brief experiments with numerous students, or experiments with fewer students over longer periods of time. The drawback is that students work under circumstances different from industrial settings although all students have worked extensively on team-based software development projects as part of their study.

Our inspiration for using role playing comes from the improvisational theater tradition and theater games originally developed as a method for training actors. The aim is to make team members adopt and apply a varied set of views, values, and rationales to facilitate the exchange of unusual ideas and promote creative thinking (Amabile et al. 1996). The characterization and function of a role frames the actions of a team member, and each role is constantly negotiated as the game progresses. Team members may improvise freely in the situation.

\subsection{Initial Role Definitions}

As Essence is intended to be lightweight, the initial definitions of the roles were very brief. We tried to make the roles self-explanatory and intuitive. The role would be presented as a personal responsibility, and the team would act the roles and use the physical space and views as they saw fit. We did not see a need for more elaborate definitions of the roles and expected them to follow naturally from function, as all except the child role were merely adaptations of preexisting roles in any agile development method.

Initially the roles were articulated in terms of functionality. The challenger was just that: a customer providing challenges to the team. Likewise, responders would meet and possibly exceed expectations when faced with challenges. The anchor was a 
facilitator and guardian of the creative process, while the child role would serve as a safety valve to let out odd ideas or discomfort with how things were progressing. The behavior of team members was expected to follow straightforwardly from these functional requirements. How this behavior was rooted in values, rationales, and personal nature was left for the team members to fill in.

In command variable terms, the first design of roles was lax, and how they would be employed was not prescribed.

We tried this approach in a project for software engineering thesis students as reported by Aaen (2008a, 2008b). In this laboratory experiment, four students worked on a software development project over 4 months. The development part alone took 2 full months.

The students used Scrum (Schwaber and Beedle 2002) as the basis for Essence and developed an IDE plug-in over four sprints. During the experiment, the students answered a questionnaire with 16 questions for each sprint. Their answers were analyzed qualitatively using a 48-node coding tree with TAMS analyzer.

Using a role obviously requires it to be well understood, but the students felt that this was not the case from the start, and this had implications for how useful they found the roles to be. One student wrote "The roles should have been clearer specified from the start to indicate their implications" and another wrote "When I finally fell into the role it worked fine, but apart from that I don't think it went very well."

Some students reported negative experiences. One of them doubted the potential in the child role: "The child role does not do a whole lot. It feels odd to thwart the other team members to create ideas." Another student criticized the responder role's responsibilities: "I am not sure the distribution of responsibilities is even. As a responder you are fairly free from responsibility."

Altogether, the group reported more positive than negative experiences from using roles. Roles generally help distribute responsibilities in the team. This was useful seen from the individual team member's perspective: "This way I have specific responsibilities and can concentrate on them." Similarly, some students observed benefits for the whole team: "The roles help distribute responsibilities meaningfully." Roles also benefit the team by supporting interactions among team members: "The roles were useful tools. I knew whom to ask and I could expect to be guided in certain situations." Individual roles had specific advantages: "Having an anchor to settle questions fast" was a factor that was helpful. Similarly, the challenger role helped make decisions: "Answers, decision making....Essence gave me authority."

On the other hand, the students found it difficult to have the roles in mind at all times: "The customer [challenger] had like a double role and you quickly forgot who was customer, and the same was true for the anchor. It was mostly when our discussions went silly that we reminded ourselves of the roles."

This experiment helped evaluate our first design of the roles. We expected roles to be intuitive and easy to learn and follow, due to being functionally defined and based on preexisting roles in agile development, but the experiment dashed this expectation. In the experiment, roles were fleeting, not always intuitive, sometimes forgotten, and hard to learn. 
The roles were not as useful to the team as hoped for, and we decided to change their design.

\subsection{Revised Role Definitions: Adding Temperaments to Roles}

We assume there is a need for more definition while keeping the acting out of roles open. Prescription must be kept at a minimum. We therefore developed a design that would be easy on choreography, still more suggestive. Values and temperaments were to be internalized deeper into the player to provide a basis for his actions. In command variable terms, the second design of roles was more defined, but the process for using them was kept open.

The idea in the new design is to define the temperament-psychological archetype - for each role, the outlook, values, and rationales of the archetype. Hopefully a deeper understanding of the temperaments will help internalize values and rationales into behaviors without becoming overly restrictive. The temperaments are used to ensure variation in perspectives among team members, to support the creation of more sophisticated software solutions in line with Tiwana and McLean's (2005) empirical study of expertise integration and team creativity.

The new role definitions are based on the temperaments associated with the generic views: fire, water, earth, and air. The four temperaments have been used for thousands of years to describe and characterize archetypal personalities.

The personality types are ideal types, constructs suggesting a particular set of values and rationales for a given role. Thus they will not describe the person playing a role, only the role itself. The archetypes are used to ensure variety among roles and comprehensiveness in the team in the sense that all major outlooks are represented to facilitate that challenges and candidate solutions are seen from diverse viewpoints.

The four temperaments are the choleric, the melancholic, the phlegmatic, and the sanguine, and we relate each of these temperaments to the logical views for which each of the Essence roles has primary responsibility.

The Choleric Responder. The choleric is associated with the fire element. Fire is energetic and associated with passion, destruction, and creation. In Essence, fire is associated with the product view. The product should bring about change by destructing what is obsolete and creating the best replacements imaginable. The product view is associated with the responder role, and consequently the responder has a choleric temperament.

The responder represents technical skills. A strong sense of ambition makes the responder strive for the best result possible, and sometimes even disregard influences they consider nuisances. The responder is enthusiastic and does not settle for the ordinary. He is not a pleaser, but plays hard to achieve success, and when faced with obstacles he musters even more energy.

The Melancholic Challenger. The melancholic is associated with the earth element. Earth is traditionally restrained and associated with the practical, physical, and sensual. In Essence, earth is associated with the project view. The project is the basis for the development effort, and provides the essential resources for the change to be brought about. The project view is associated with the challenger role, and consequently the challenger has a melancholic temperament. 
The challenger is the customer and represents needs and resources for the project. The challenger is reflective and has far-reaching thoughts. He is kind and pensive.

The Phlegmatic Anchor. The phlegmatic is associated with the water element. Water is traditionally stoic and associated with calm, rationality, and reason. In Essence, water is associated with the process view. The process offers support for the work in terms of tools, techniques, and procedures for idea generation, development, and evaluation activities. The process view offers a Swiss Army Knife or Junior Woodchucks Guidebook for the team. The process view is associated with the anchor role, and consequently the anchor has a phlegmatic temperament.

The anchor is a facilitator and represents skills for moderation, negotiation, and inspiration. He is only weakly affected by impressions and rarely engages emotionally. He is a calm observer, friendly and reliable, and acts when needed.

The Sanguine Child. The sanguine is associated with the air element. Air is traditionally fleeting and was associated by Plato with mobility and ability to penetrate. In Essence, air is associated with the people view. The people view is used for evaluating the product against perceived or real uses, and for provoking radically new ideas or conceptions about the environment to be changed. The people view is associated with the child role, and consequently the child has a sanguine temperament.

The child is the jester in the project and represents untamed, irresponsible, and possibly revolutionary behavior. The child is fast and eager when excited-he reacts immediately, but forgets again soon. He often engages in the part more than the whole and does not always understand the depth of a matter.

\section{Second Experiment with Roles: The Intensive Essence Course}

The second experiment took place as part of a new software innovation course for Computer Science students (third year), Software Engineering students (fourth year), and International Master's students. A total of 61 students attended the course-25 from Computer Science, 17 from Software Engineering, 15 from the International Master's, and 4 other students.

The Essence part consisted of three lectures (two on Essence and one on Scrum ) followed by two full days of work on a major challenge. Our students are always organized in groups of four or five persons, and each group shares a permanent room with another group. Every student, therefore, knows the people in the room and is used to working closely with half of them. For practical reasons, we chose to form groups by merging the preexisting collocated groups into one.

The two-day challenge was to design a superior project management tool for innovative teams using Scrum. The tool should have extraordinary features and support working with idea development and idea administration. Via a number of idea development sessions, the groups would produce a product vision over the two days.

The introduction to Essence included a presentation of the roles and temperaments. Every group appointed one anchor and one challenger, while all remaining group members were responders. Every group member wore a badge at all times with the 
name of their role printed in corresponding colors: red for responders, green for challengers, and blue for anchors. The badges were constant reminders of each person's role and temperament.

The pedagogy of this part of the course differed markedly from conventional courses. Although the students were exhausted by the end of two intensive days, they overall worked with enthusiasm and focus in a free atmosphere, and many students demonstrated great zest in the activities. Evaluations after the course were mainly positive or constructively critical.

The two days consisted of four blocks, each with group work ending in plenum presentations of the results. Each block used several different techniques for developing and maturing ideas including variants of well-known techniques such as traditional brainstorming and six thinking hats (de Bono 2000). The first two blocks were devoted to diverging idea generation, while the latter two were used for converging and presenting the final ideas.

\section{Evaluation of the Revised Roles}

Immediately after the two-day challenge, we issued a questionnaire to the students. The questionnaire covered simple demographics: age, study, and role. All students were male. The rest of the questionnaire focused on evaluations of the following:

- The respondent's own and the other roles in the group

- The use of views

- Each of the nine techniques used in the four blocks

- Overall views on idea-generation techniques, idea-evaluation-techniques, and Essence

A total of 38 questions were asked. Most of them were yes/no or five-point Likert scale, and each group of questions on roles, views, and individual techniques ended in a free-format question calling for additional comments. The data were collected over 2 weeks, and we received 39 responses corresponding to a response rate of over 60 percent. No incentives were used, except polite requests at lectures and gentle e-mail reminders.

Approximately one month later, the students were encouraged to prepare a written report as part of their preparations for exam. They were asked to give an evaluation of their experiences during the two-day intensive part of the course. The report was to be prepared in self-chosen groups of not more than three and be three to six pages long. The reports would not be graded, but they would act as a starting point for the oral exam. Altogether 54 students used this option and wrote 27 reports. Of these, 6 were written by single students, 15 by pairs, and the remaining 6 by groups of three.

Table 1 presents the data from the questions on the three permanent roles. About 85 percent of the students understood their own role well or very well. Challengers appear to have had slightly more problems understanding their roles, probably because few had relevant experience for this role.

Around 65 percent of the students were able to apply their own role. One anchor and one challenger were unable to do this. As these two roles are unique to a team, this suggests major problems. Both students came from the same group and no one 
else from this group answered the questionnaire. This group may have had massive problems, but whether or not these problems were related to the roles is not known.

Around half found their role useful. One in four was neutral, and one in four was negative. There are marked differences from role to role. Responders are overall neutral or positive (around 55 percent are positive), whereas more than half of the anchors are neutral and the rest positive. Challengers are split, half are positive, while the other half are negative, indicating the difficulties students face when playing this role.

Well over half of the students found the other roles helpful, while less than a third did not. Half of the challengers found the other roles helpful, while three out of four anchors viewed them as positive.

Table 1. Evaluation of Roles

\begin{tabular}{|c|c|c|c|c|c|c|c|c|c|c|c|c|}
\hline & \multicolumn{6}{|c|}{ Did you understand your own role? } & \multicolumn{6}{|c|}{ Were you able to apply your own role? } \\
\hline & \multicolumn{3}{|c|}{ (No) } & \multicolumn{3}{|c|}{ (Yes) } & \multicolumn{3}{|c|}{ (No) } & \multicolumn{3}{|c|}{ (Yes) } \\
\hline & 1 & 2 & 3 & 4 & 5 & $\sum$ & 1 & 2 & 3 & 4 & 5 & $\sum$ \\
\hline Anchor & 0 & 0 & 0 & 5 & 2 & 7 & 0 & 1 & 1 & 3 & 2 & 7 \\
\hline Challenger & 0 & 0 & 1 & 5 & 0 & 6 & 1 & 0 & 2 & 3 & 0 & 6 \\
\hline Responder & 0 & 1 & 3 & 14 & 8 & 26 & 1 & 4 & 3 & 15 & 3 & 26 \\
\hline \multirow[t]{4}{*}{$\sum$} & 0 & 1 & 4 & 24 & 10 & 39 & 2 & 5 & 6 & 21 & 5 & 39 \\
\hline & \multicolumn{6}{|c|}{ Did you find your own role helpful? } & \multicolumn{6}{|c|}{ Did you find the other roles helpful? } \\
\hline & \multicolumn{3}{|c|}{ (No) } & & \multicolumn{2}{|c|}{ (Yes) } & \multicolumn{3}{|c|}{ (No) } & \multicolumn{3}{|c|}{ (Yes) } \\
\hline & 1 & 2 & 3 & 4 & 5 & $\sum$ & 1 & 2 & 3 & 4 & 5 & $\sum$ \\
\hline Anchor & 0 & 0 & 4 & 2 & 1 & 7 & 0 & 0 & 2 & 3 & 2 & 7 \\
\hline Challenger & 1 & 2 & 0 & 3 & 0 & 6 & 1 & 1 & 1 & 3 & 0 & 6 \\
\hline Responder & 2 & 5 & 5 & 8 & 6 & 26 & 1 & 8 & 4 & 7 & 6 & 26 \\
\hline$\sum$ & 3 & 7 & 9 & 13 & 7 & 39 & 2 & 9 & 7 & 13 & 8 & 39 \\
\hline
\end{tabular}

Those who saw the other roles as positive also understood their own role, were able to apply it, and found it helpful. We saw some differences between the studies. Computer Science students reported less positive experiences compared to International Master's and Software Engineering students. These differences may be related to value differences between studies and nationality, as we see no major differences related to other demographic factors.

The qualitative study offers deeper insights into how students experienced the roles. We coded the 27 reports for comments on roles and temperaments using TAMS analyzer to supplement the questionnaire data. Space limitations allow for only a few comments here.

The reports were written at a time where the students had gained a deeper understanding of the intentions in Essence. This is reflected in their comments, where roles are generally accepted as a promising idea.

Some point to difficulties in using the roles ("A sense of like-mindedness in our group made the roles seem forced"), while others point to lack of experience("A reason why the roles were not that useful could be due to us being novices"). 
Several point to advantages in using roles to allocate responsibilities and ensure focus. Some point to advantages of different perspectives: "We discovered that sometimes an unusual point of view can bring better solutions than a classical one. It demonstrated the advantages of having different personalities, opinions, and technical backgrounds in the same team."

A number of reports comment on the temperaments as a source of problems. This quote sums up most of these views: "The team did not succeed very well in implementing the roles. It seems that the two main reasons for this are: 1) the team members did not have sufficient time to get used to the roles 2) a probably more important reason could be that we divided the roles more or less randomly or at least not in accordance with the personality/nature of the team members. Although the roles are indeed roles, we cannot expect the personality...to fit the nature of the roles perfectly."

\section{Lessons and Implications}

The second design of roles sought to build values deeper into the roles based on archetypal temperaments. We wanted a clearer definition of the roles without prescribing action.

The experiment shows that the new design also has problems. Generally roles are perceived as potentially useful, offering diversity to the team. Roles are, however, still hard to learn and easy to forget. These problems might be handled via pedagogical means, but unfortunately the new design introduced new and seemingly fundamental problems: Students complained that roles sometimes felt forced, and they consistently mentioned a difference between personal temperament and role temperament as a problem.

Therefore, we conclude that we need to change the roles a third time. We still want Essence to be lightweight, fun, and easy to use, so our next combination of the command variables must keep this objective in mind. We believe that the third design of roles should be lax, but the process for using them should be somewhat more prescriptive, although still lightweight.

Presently our ideas are to meld the temperaments into the views rather than the roles, and to define the views more clearly in terms of values and how they are used. This will strengthen the process definition in return for relaxing the role definition.

To achieve this, we will put more focus on the people view and the child role. These two will be central in most idea generation sessions. We will use a bit more choreography: Games will take form as a series of steps beginning at the people view, where scenarios are developed without constraints by all team members taking the child role. The next step will be realistic construction at the product view led by the responders, where implementation options are developed; and the last step will be a critical examination chaired by the challenger at the project view, where the dreams are evaluated and decided on. This sequence will be iterated as needed. Temperament thus follows the view. One view (and one temperament) at a time will take the lead. All team members will have the same temperament while at the same view. No team member will be required to have a temperament different from any other, but each role will continue to have special responsibilities. 
The new design introduces new dangers to Essence: The interaction between views might be weakened, although the use of each view might be strengthened. It might also make Essence more sequential and rigid, although each step will be more focused. These dangers will be addressed in coming experiments.

\section{Conclusion}

Essence is developed iteratively as we gain experience from using it. Method design involves great complexities, and evaluating the design is complicated as too many factors are involved to single each out for systematic testing.

We use command variables as learning instruments to reason about design alternatives and learn from experiments. We cannot use command variables for systematic variation and testing, but we use them to at least have an idea about what we are changing, why we do this, and to evaluate pragmatically the implications of these variations.

Every design tested here is one that we have believed in completely. When we design, we need to passionately believe the new to be an improvement, but to some extent this is in conflict with the traditional view of the experimental researcher as a neutral observer. This is one of the challenges in design science. Our use of design variables seeks to balance this conflict.

Future research will flesh out and evaluate the third design of roles in Essence. We will try to include real-life projects in our experiments to supplement the experiments involving students.

\section{Acknowledgments}

Thanks go to Jeremy Rose, my colleague on the software innovation course, and to our students for their patience, tolerance, and generous comments. I also would like to thank the anonymous reviewers for insightful comments and suggestions.

\section{References}

Aaen, I.: Essence: Facilitating Agile Innovation. In: Abrahamsson, P., Baskerville, R., Conboy, K., Fitzgerald, B., Morgan, L., Wang, X. (eds.) Agile Processes in Software Engineering and Extreme Programming, pp. 1-10. Springer, Berlin (2008a)

Aaen, I.: Essence: Facilitating Software Innovation. European Journal of Information Systems 17(5), 543-553 (2008b)

Adamides, E.D., Karacapilidis, N.: Information Technology Support for the Knowledge and Social Processes of Innovation Management. Technovation 26(1), 50-59 (2006)

Amabile, T.M., Conti, R., Coon, H., Lazenby, J., Herron, M.: Assessing the Work Environment for Creativity. Academy of Management Journal 39(5), 1154-1184 (1996)

Bernstein, L., Yuhas, C.M.: People, Process, Product, Project: The Big Four. In: Bernstein, L., Yuhas, C.M. (eds.) Trustworthy Systems Through Quantitative Software Engineering, pp. 39-71. John Wiley \& Sons, Inc., New York (2005) 
Chang, C.M.: Collaborative, Heuristic and Normatively Guided Techniques to Creativity. In: Proceedings of the Portland International Conference on Management of Engineering \& Technology (PICMET 2008), July 27-31, pp. 656-663. IEEE Computer Society, Los Alamitos (2008)

de Bono, E.: Six Thinking Hats. Penguin, London (2000)

de la Barra, C., Crawford, B.: Fostering Creativity Thinking in Agile Software Development. Springer, Berlin (2007)

Deshpande, N., de Vries, B., van Leeuwen, J.P.: Collocated, Multi-Disciplinary, Collaborative Designspace: An overview. In: van Leeuwen, J.P., Timmermans, H.J.P. (eds.) Developments in Design \& Decision Support Systems in Architecture and Urban Planning, pp. 253-268. Eindhoven University of Technology, Eindhoven (2004)

Do, E.Y.-L., Gross, M.D.: Environments for Creativity: A Lab for Making Things. In: Proceedings of the 6th ACM SIGCHI Conference on Creativity \& Cognition, Washington, DC, June 13-15, pp. 27-36 (2007)

Fortino, A.: A Pattern Language for Innovation Management. In: Proceedings of the Portland International Conference on Management of Engineering \& Technology (PICMET 2008), July 27-31, pp. 415-419. IEEE Computer Society, Los Alamitos (2008)

Greene, S.L.: Characteristics of Applications that Support Creativity. Communications of the ACM 45(10), 100-104 (2002)

Hevner, A.R., March, S.T., Park, J., Ram, S.: Design Science in Information Systems Research. MIS Quarterly 28(1), 75-105 (2004)

Highsmith, J.: Agile Project Management: Creating Innovative Products. Addison-Wesley, Boston (2004)

Highsmith, J., Cockburn, A.: Agile Software Development: The Business of Innovation. Computer 34(9), 120-127 (2001)

Hohmann, L.: Innovation Games: Creating Breakthrough Products Through Collaborative Play. Addison-Wesley Professional, Upper Saddle River (2006)

Huczynski, A.: Encyclopedia of Development Methods. Gower, Aldershot (2001)

Johansson, M., Fröst, P., Brandt, E., Binder, T., Messeter, J.: Partner Engaged Design: New Challenges for Workplace Design. In: Proceedings of the Participatory Design Conference, Malmo, Sweden, June 23-25, pp. 162-172 (2002)

Judy, K.H., Krumins-Beens, I.: Using Agile Practices to Spark Innovation in a Small to Medium Sized Business. In: Proceedings of the 40th Annual Hawaii International Conference on System Sciences. IEEE Computer Society, Los Alamitos (2007)

Kristensen, T.: The Physical Context of Creativity. Creativity and Innovation Management 13(2), 89-96 (2004)

Larssen, A.T., Robertson, T., Edwards, J.: The Feel Dimension of Technology Interaction: Exploring Tangibles Through Movement and Touch. In: Proceedings of the First International Conference on Tangible and Embedded Interaction, Baton Rouge, LA, February 15-17, pp. 271-278 (2007)

Leenders, R.T.A.J., van Engelen, J.M.L., Kratzer, J.: Systematic Design Methods and the Creative Performance of New Product Teams: Do They Contradict or Complement Each Other? Journal of Product Innovation Management 24(2), 166-179 (2007)

Lewis, M., Moultrie, J.: The Organizational Innovation Laboratory. Creativity and Innovation Management 14(1), 73-83 (2005)

Mahaux, M., Maiden, N.: Theater Improvisers Know the Requirements Game. IEEE Software 25(5), 68-69 (2008) 
Maiden, N., Manning, S., Robertson, S., Greenwood, J.: Integrating Creativity Workshops into Structured Requirements Processes. In: Proceedings of the 2004 Conference on Designing Interactive Systems: Processes, Practices, Methods, and Techniques, Cambridge, MA, August 1-4, pp. 113-122 (2004)

Maiden, N., Robertson, S.: Integrating Creativity into Requirements Processes: Experiences with an Air Traffic Management System. In: Proceedings of the 13th IEEE International Conference on Requirements Engineering, Paris, August 29-September 2, pp. 105-114 (2005)

Maiden, N., Robertson, S., Gizikis, A.: Provoking Creativity: Imagine What Your Requirements Could Be Like. IEEE Software 21(5), 68-75 (2004)

Maiden, N., Robertson, S., Robertson, J.: Creative Requirements: Invention and its Role in Requirements Engineering. In: Proceeding of the 28th International Conference on Software Engineering, Shanghai, China, May 20-28, pp. 1073-1074 (2006)

Mich, L., Anesi, C., Berry, D.M.: Requirements Engineering and Creativity: An Innovative Approach Based on a Model of the Pragmatics of Communication. In: Proceedings of the Requirements Engineering: Foundation for Software Quality (REFSQ) Workshop, Riga, Latvia (2004)

Nerur, S., Balijepally, V.: Theoretical Reflections on Agile Development Methodologies. Communications of the ACM 50(3), 79-83 (2007)

Pressman, R.S.: Software Engineering: A Practitioner's Approach. McGraw-Hill Higher Education, Boston (2005)

Rittel, H.W.J., Webber, M.M.: Dilemmas in a General Theory of Planning. Policy Sciences 4(2), 155-169 (1973)

Satzinger, J.W., Garfield, M.J., Nagasundaram, M.: The Creative Process: The Effects of Group Memory on Individual Idea Generation. Journal of Management Information Systems 15(4), 143-160 (1999)

Schwaber, K., Beedle, M.: Agile Software Development with Scrum. Prentice Hall, Upper Saddle River (2002)

Shneiderman, B.: User Interfaces for Creativity Support Tools. In: Proceedings of the Third Conference on Creativity \& Cognition, Loughborough, United Kingdom, October 11-13, pp. 15-22 (1999)

Shneiderman, B.: Creativity Support Tools. Communications of the ACM 45(10), 116-120 (2002)

Shneiderman, B.: Creativity Support Tools: Accelerating Discovery and Innovation. Communications of the ACM 50(12), 20-32 (2007)

Simon, H.A.: The Sciences of the Artificial. MIT Press, Cambridge (1996)

Swartjes, I.M.T., Vromen, J.A.F.: Emergent Story Generation: Lessons from Improvisational Theater. In: Proceedings of the AAAI Fall Symposium on Intelligent Narrative Technologies, Arlington, VA, November 9-11, pp. 146-149 (2007)

Terrenghi, L., Fritsche, T., Butz, A.: The EnLighTable: Design of Affordances to Support Collaborative Creativity. In: Butz, A., Fisher, B., Krüger, A., Olivier, P. (eds.) SG 2006. LNCS, vol. 4073, pp. 206-217. Springer, Heidelberg (2006)

Thomas, J.C., Lee, A., Danis, C.: Enhancing Creative Design Via Software Tools. Communications of the ACM 45(10), 112-115 (2002)

Tiwana, A., McLean, E.R.: Expertise Integration and Creativity in Information Systems Development. Journal of Management Information Systems 22(1), 13-43 (2005)

Vaishnavi, V., Kuechler, W.: Design Research in Information Systems, January 20 (2004), last updated August 16, 2009,

http: / / ais . affiniscape. com/displaycommon. $c$ fm?an=1\&

subarticlenbr=279 (accessed November 24, 2009)

Yardley-Matwiejczuk, K.M.: Role Play: Theory and Practice. Sage, London (1997) 


\section{About the Author}

Ivan Aaen is an associate professor of computer science at Aalborg University, Denmark. His interests include software innovation, agile software engineering, and information systems. He holds a Ph.D. in computer science from Aalborg University and is a member of the ACM and IEEE Computer Society. He can be reached at aaen@acm.org. 